\title{
Impact of Leadership Styles on Employee Adaptability in Call Center: A Perspective of Telecommunication Industry in Malaysia
}

\author{
Rajendran Muthuveloo ${ }^{1}$, Kanagaletchumy Kathamuthu ${ }^{1} \&$ Teoh Ai Ping ${ }^{1}$ \\ ${ }^{1}$ Graduate School of Business, Universiti Sains Malaysia, Penang, Malaysia \\ Correspondence: Rajendran Muthuveloo, Graduate School of Business, Universiti Sains Malaysia, Malaysia. \\ E-mail: rmuthuveloo@gmail.com
}

Received: July 28, 2013 Accepted: January 9, 2014 Online Published: March 31, 2014

doi:10.5539/ass.v10n7p96

URL: http://dx.doi.org/10.5539/ass.v10n7p96

\begin{abstract}
The purpose of this study is to find how employees adapt to different leadership styles in call centers in the telecommunication industry. This exploratory research was conducted among employees in call centers in the telecommunication industry to test the relationship between Leadership Styles and Employee Adaptability. The researcher used statistical inference and more specifically Linear Regression to test the relationship between the two variables. Results indicated that all the three Leadership Styles have an influencing role on the Employee Adaptability. Due to company policy, high volume of responses was not achieved. Job functions of the employees not directly reporting to their managers causing employee not interested in responding the surveys. Also, this study did not investigate the maturity level of the employees which has influence on the adaptability. And, the researcher was not able to get responses from all employees working in shifts. Few studies have been explored in the Leadership Styles and Employee Adaptability, this study expands our knowledge of leadership styles effect on employees' adaptability in call centers in telecommunication industry in Malaysia.
\end{abstract}

Keywords: leadership styles, employee adaptability, telecommunication industry

\section{Introduction}

The greatest asset for a Call center is its employees. Therefore, any changes in the environment that will affect the employees' adaptability must be treated with high regards. In general, the employees' performance and motivation may decline in long term, but effective leadership approaches helps to minimize this impact.

Ivancevich, Konopaske and Matteson (2008) described leadership as the process of influencing others to facilitate the attainment of organizational relevant goals. Good leadership assists in effectively meeting job-related demands, creating higher-performing teams, developing loyal, committed and highly motivated employees. Researchers have developed various leadership styles which can assist aspiring leaders to understand which styles they should adopt and liked by their followers.

In order to remain effective, the leader must be a person of great character with integrity and must make a daily commitment to lead by understanding the employees. Whether a leader manages a small team or a large organization, the leader should identify the leadership styles that suits best for him and his employees. Consciously or subconsciously, a leader uses some of the leadership styles which go along with their personality. However, understanding the different styles and its impact can help the leaders to develop their own personal leadership style that will be accepted by the followers.

The perceptions that certain traits or personality characteristics that are associated with good leaders or that some are born to lead are no longer accepted (Nahavandi, 2006). In this modern age, leadership theorists have accepted that leadership is based on behaviors and skills that can be learned. With this in mind, there are a few factors that had influenced the adaptability and understanding of leadership. This research will look at some of the most common and popular leadership styles being practiced in this modern era.

\section{Problem Statement}

Leaders determine the direction of an Organization. When different leadership style takes place, it affects the employee performance either positively or negatively. The employees will act in a supportive manner towards their leader if the employees feel and accept that the leader will lead the organization in the direction that will be benefiting the organization and themselves. Unfortunately, at times it is more likely that employees will 
experience incongruence among their feelings, thoughts, and actions towards their leaders which can create a challenging atmosphere. On the other hand, leaders face increased pressure to respond to the employees' mood congruence and likely to practice an inappropriate leadership approach to their employees. As a result, this affects the employees' adaptability towards their leader's styles and approach which resulted in the employee performance degradation and creates resistance.

Therefore, the Researcher intends to investigate the adaptability effect of the employees towards leaders' different approaches in the call centers of telecommunication industry and provide specific strategies for the leaders to enhance their employees' adaptability.

\section{Literature Review}

\subsection{Leadership Styles}

Effective leadership is an important element for a successful organization. Leadership approaches that are not well perceived or accepted by employees will lead to a decreased organizational efficacy. An organization's performance can move unsteadily during and after a leadership change if an appropriate leadership is not demonstrated. Thus, the leaders play a very important role in determining the employee adaptability.

Transactional leadership is really a type of management, not a true leadership style, because the focus is on short-term tasks. Burns (cited in Boehnke et al., 2003) contrasted transactional and transformational leadership, believing that they lie at opposite ends of a continuum. He found that the transactional leaders work within the organizational culture as it exists but the transformational leader changes the organizational culture. Bass (cited in Boehnke et al., 2003) also expressed that transactional leaders do not voluntarily involve with employees' work until any failure occurs, whereas transformational leaders act as role models for employees, motivate them, and stimulate their intelligence.

A model derived from Bass and Avolio (1990) as shown below, explains that transactional leaders pursues a cost benefit, economic exchange to meet the employees present material and psychic needs in return for the services provided by the employees. While Bass also stressed that the leaders who recognizes the transactional needs in the potential employees but also tends to go beyond, seeking to increase and satisfy higher needs and engage the followers at their full capabilities to achieve a higher level of needs according to Maslow's hierarchy of needs. Bass explained that in order to achieve a performance beyond expectation, a transformational leader should idealize influence, individualized consideration by mentoring, provides inspirational motivation through team spirit and stimulates intellectuals in creativity and innovation among employees.

\subsection{Transformational Leadership}

One leading theory of leadership, known as transformational leadership, has gained prominence in the post-industrial business landscape. According to Boehnke et al. (2003) and also many other researchers such as Xenikou and Simosi (2008), Felfe and Schyns (2006), Avolio et al. (2009) supported the work of Bass and Burns that transformational leadership raises leadership to the next level. Its elements encourages followers to commit to a shared vision and goals of an organization or unit, challenging them and developing their leadership capacities by mentoring, coaching and by providing both challenge and support.

Transformational leadership occurs when a leader with charisma and vision transforms his/her followers becoming highly motivated and trust the leader whilst demonstrates behaviors that contribute to the achievement of organizational goals. In a research conducted by De Jong and Den Hartog (2007) and Aragon-Correa et al. (cited in Raja \& Palanichamy, 2011), addressed that transformational leadership draws more attention in organizations since it contributes to the innovation, organizational learning and employees' creativity skills. Raja and Palanichamy (2011) in their research concluded that transformational leadership best suits for employee performance improvement. In addition, Birasnav and Dalpati (2009) research also concluded that transformational leaders have potential to affect their employees' perception of human capital benefits. Such human capital benefits have high individual return on investment, opportunity to participate in high profile project and increase in status and authority (Motley, 2007).

Transformational leaders create individual and team spirit among employees as they show interest and optimism at employee through coaching, encouraging and supporting. According to a research by Nemanich and Keller (2007), they concluded that leaders who possess the characteristics of inspirational motivation enhance the employees' goal or job performance to achieve the target set by the management. As a result, the leaders improve employees' performance while performing job activities and produce a high return on investment from employees (Boerner et al., 2007). 
In short, transformational leaders are exceptionally motivating and they are trusted by employees. When every employee in a team trusts their leader, the leaders achieve the organization goals easily.

\subsection{Situational Leadership}

Employees prefer a leader who can guide and make decision instantaneously. However, the employee's motivation and their capability becomes an important factor that affects the situational decision. A study by Roy (2006) concluded that Situational Leadership can be used as a framework to furnish leaders with the guidance to coach their employees throughout the performance coaching cycle. During the initial meeting, Situational Leadership guides the leader in setting the degree of participation for the planning and goal-setting process. During the rest of the period, it guides the leader in each interaction with the follower. This also supported in a research conducted by Mujtaba (2009) who concluded that using situational leadership skills, managers tend to remain focused on the readiness of their employees and coaches them according to their level of maturity while adapting their communication styles to the way employees like to be treated. In this research, Mujtaba (2009) also provided an overview of situational leadership and linked it to diversity management and coaching of employees in the organization.

Situational Leadership combines four different leadership styles into a practical and methodical order for managers to lead and manage staff effectively. It teaches leaders to diagnose the needs of an individual or a team, and use the appropriate leadership approach to respond accordingly.

\subsection{Employee Adaptability}

A leader must understand the preferred leadership styles, how the employees adapt to the leaders and their effect on the performance (Wilson, 2010). Although the employee adaptability can be related to many other factors, the Researcher will focus the employee adaptability towards different leadership styles from the following three main approaches and their relation to the employee performance, turnover, participation and relationship with manager.

\subsection{Employee Performance}

In research conducted by Liu and Batt (2010) on employee performance cited that managers should seriously give importance to the employee performance improvement by providing individualized instruction and guidance. This is also supported by Heslin, Vandewalle and Latham (2006) research who stressed that managers must not only manage their teams but also coach the individual employees for their betterment. The close guidance of the manager is appreciated and the portrayed leadership styles are accepted by the employees in which they tend to follow the instructions given by their leader without much hesitation.

A research conducted by Chen and Silverthorne (2005) confirmed that an employee's ability and their willingness to perform affect each other. The finding suggested that organizations should have the right leaders to give employees suitable training to increase their ability and productivity. Thus, the leaders have to practice more adaptable leadership approach in order to encourage employees to perform.

\subsection{Turnover}

The turnover issue has been a critical organizational issue for some time. Turnover intention has been emphasized as an important factor for the financial performance of organizations and has been influenced by various reasons in organizations (Lambert et al., 2001).

Employees are most likely opt turnover when both their psychological well-being and their job satisfaction are low (Wright \& Bonett, 2007). Align with this statement, a survey conducted by Truskie (2008) found that the number one reason employees leaves a company is because of their manager. Employee turnover can often be attributed to poor managerial performance, low emotional intelligence and ineffective leadership. This is also supported by Joo and Park (2009) through their findings that leadership factor is one of the main reason for turnover intention.

In another survey reported in a Workforce Magazine (cited in Carruthers, 2010) stated the results of interviews with 20,000 departing workers indicated the main reason employees chose to leave is due to poor management. While a HR magazine (cited in Carruthers, 2010) found that 95\% of exiting employees attributed their search for a new position due to an ineffective leadership. Therefore, it is very significant that leaders hold important role in managing and retaining the employees.

\subsection{Employee Participation}

Employee participation actually increases organizational commitment and job satisfaction, and in fact, during an organizational change it fosters higher levels of change acceptance and effectiveness (Sagie \& Koslowsky, 1996). This can be achieved through an effective leadership styles. 
With the trends moving toward employee empowerment, the leader's relationship with employees becomes more cohesive. Employees tend to feel more empowered when they are asked for input about a particular task concerning them rather than when they were told exactly how to do something. But not all employees are alike, thus, a leader needs to assess an employee's ability and motivation in order to get the employees to participate and commit in their jobs. This statement correlates with the research done by Walsh and Taylor (2007) who concluded that affective commitment by employees are seen as a strong predictor for employee attitudes and behavioral intentions that brings them to participate in working environment.

\subsection{Employee-Manager Relationship}

Gill (2007) describes good employee-management relationship is the key to the success of a hospitality organization. In a research conducted by Gill (2007) he concluded that the employees trust towards managers has a significant impact on their job satisfaction which describes the level of participation of employees with their managers in performing their jobs. Thus, the leaders should practice the appropriate leadership styles but McCann (2009) stresses that leaders cannot just take one style and think it will work for everyone. An effective leader is able to alter their style by adopting an appropriate mix of task and relationship behavior to maintain the connection with the employees.

A good leadership is understood to increase the likelihood of having a more effective employee-manager relationship at workplace. This supports the findings by Snell and Dickson (2010) that employees have reacts positively when managers implemented good leadership practices, such as providing clear direction, coaching and advancing the professional development of employees.

\subsection{Hypotheses}

The literature review provides an overview on the three types of leadership styles and employee adaptability. Based on the information, a theoretical framework was formed and the following hypotheses were developed.

- Hypotheses 1: Leadership styles have significant influence on Employee Adaptability.

- Hypotheses 2: Transactional Leadership has significant influence on Employee Adaptability.

- Hypotheses 3: Transformational Leadership has significant influence on Employee Adaptability.

- Hypotheses 4: Situational Leadership has significant influence on Employee Adaptability.

- Hypotheses 5: Transactional, Transformational and Situational Leadership styles have significant influence on Performance.

- Hypotheses 6: Transactional, Transformational and Situational Leadership styles have significant influence on Turnover.

- Hypotheses 7: Transactional, Transformational and Situational Leadership styles have significant influence on Participation.

- Hypotheses 8: Transactional, Transformational and Situational Leadership styles have significant influence on Relationship with Manager.

\section{Methodology}

\subsection{Research Design}

The purpose of this study is hypotheses testing that is to test the relationship between the independent variables and dependent variables. This study focus on employees in call centers. The investigation was done using regression analysis. The sampling was based on probability that the sample size represented the population. The research was performed with interference that no controlled and environment and is performed in one time. The data was collected using questionnaires with Likert scale and employees demographic used ordinal scale. The analysis was performed using hypotheses testing.

The sample comprises of employees in call centers in the telecommunication industry. The researcher approached the organizations and explained to the management and employees about the study. The questionnaire used 5-point Likert scale for most of the questions. Sample size greater than 30 and less than 500 is suitable for most researches and generally, the number of samples should be 10 times the number of variables studied (Sekaran, 2003).

\subsection{Pilot Study}

The questionnaire was constructed based on the literature review. A pilot study was conducted in which the questionnaires were randomly distributed to call centers in the telecommunication industry. A response of 20 samples was collected. The reliability was tested and the Cronbach Alpha read more than 0.5 which indicated the 
questionnaire was reliable.

\subsection{Final Study}

In the final study, the questionnaires were distributed to call centers in the telecommunication industry. A total of 104 feedbacks were obtained. The collected responses were subjected to factor analysis, and followed by reliability analysis before proceeding to regression analysis.

\section{Findings and Analysis}

\subsection{Demographic Analysis of the Respondents}

A total of 104 employees responded for this study. The demographic profile of the respondents is explained below and the summary of the information can be seen in Table 1.

\subsubsection{Age}

Respondent's age is factored in this survey to understand the age range of the Call Center employees' and how they adapt to the different leadership styles respectively. Respondents less than 25 years old consists of $12.5 \%$, while the respondents between 26 and 30 years consist of $48.1 \%$ and group between 31 and 35 years old constituted $26.9 \%$. Lastly, the respondents aged between 41 and 45 years constituted $1 \%$ only.

\subsubsection{Gender}

In respect to the gender, there were a total of 60 female and 44 male employees participated in this study.

\subsubsection{Education}

The respondents were classified into four groups. The high school respondents constituted only $1 \%$, respondents with certificate or diploma constituted $20.2 \%$, graduates with bachelor degree was $68.3 \%$ and with master degree was $10.6 \%$.

\subsubsection{Position}

Position is referring to the position in which the respondents are working in the call centers. The positions are classified into four groups i.e. non-management, lower-management, middle-management and senior management. The groups constituted $40.4 \%, 47.1 \%, 11.5 \%$ and $1 \%$ respectively.

\subsubsection{Experience}

The experience refers to the number of years the employee has been in the position. It is classified into five groups i.e. less than 5 years, 5 to 10 years, 11 to 15 years, 16 to 20 years and above 20 years. The findings constituted $43.3 \%, 49.0 \%, 5.8 \%, 1.0 \%$ and $1.0 \%$ respectively.

\subsubsection{Type of Organization}

Type of organization refers to the category of the company in the telecommunication industry i.e. Foreign Owned Multinational Corporation, Local Public Listed (PLC Bhd) and Local Organization (Sdn Bhd). They constitute 1\%, $88.5 \%$ and $10.6 \%$ respectively. 
Table 1. Summary of demographic profile

\begin{tabular}{|c|c|c|c|}
\hline Demographic Profile & Description & Frequency & Percent \\
\hline \multirow[t]{5}{*}{ Age } & $21-25$ & 13 & 12.5 \\
\hline & $26-30$ & 50 & 48.1 \\
\hline & $31-35$ & 28 & 26.9 \\
\hline & $36-40$ & 12 & 11.5 \\
\hline & $41-45$ & 1 & 1 \\
\hline \multirow[t]{2}{*}{ Gender } & Male & 60 & 57.7 \\
\hline & Female & 44 & 42.3 \\
\hline \multirow[t]{4}{*}{ Education Level } & High School & 1 & 1 \\
\hline & Certificate/Diploma & 21 & 20.2 \\
\hline & Bachelor's Degree & 71 & 68.3 \\
\hline & Masters Degree & 11 & 10.6 \\
\hline \multirow[t]{4}{*}{ Position } & Non-management & 42 & 40.4 \\
\hline & Lower management & 49 & 47.1 \\
\hline & Middle management & 12 & 11.5 \\
\hline & Senior management & 1 & 1 \\
\hline \multirow[t]{5}{*}{ Experience } & Less than 5 years & 45 & 43.3 \\
\hline & 5 to 10 years & 51 & 49 \\
\hline & 11 to 15 years & 6 & 5.8 \\
\hline & 16 to 20 years & 1 & 1 \\
\hline & Above 20 years & 1 & 1 \\
\hline \multirow[t]{3}{*}{ Type of Organization } & Foreign Owned Multinational Corporation & 1 & 1 \\
\hline & Local Public Listed (PLC-Bhd.) & 92 & 88.5 \\
\hline & Local Organization (Sdn. Bhd.) & 11 & 10.6 \\
\hline
\end{tabular}

\subsection{Factor Analysis}

The factor analysis is a statistical technique used to find whether the variables observed are related to an unobserved variable which are called as factors. By using this technique, generally, the variances are summarized into smaller set, which provides the key information of the variables. This analysis is performed as a test of validity of measures for both dependent and independent variables.

The findings of this study showed that the KMO (Kaiser-Meyer-Olkin) value read above 0.5 for all the three Independent Variables. The Transactional Leadership constituted 0.776, Transformational Leadership constituted 0.837 and Situational Leadership is 0.819 . The summary of the KMO and Barlett's Test is shown below.

The analysis for Dependent Variables showed the KMO (Kaiser-Meyer-Olkin) value for all the variables are above 0.5. Employees' Performance, Turnover, Participation and Relationship with Manager showed 0.897, 0.682, 0.888 and 0.755 respectively. The summary of the KMO and Barlett's Test is shown below. 
Table 2. Summary of KMO and Barlett's test for independent variable and dependent variable (leadership styles)

\begin{tabular}{lcc}
\hline Independent variables & KMO (Kaiser-Meyer-Olkin) & Significant (Sig) \\
\hline Transactional Leadership & 0.776 & 0.000 \\
Transformational Leadership & 0.837 & 0.000 \\
Situational Leadership & 0.819 & 0.000 \\
\hline Dependent variables & KMO (Kaiser-Meyer-Olkin) & Significant (Sig) \\
\hline Performance & 0.897 & 0.000 \\
Turnover & 0.682 & 0.000 \\
Participation & 0.888 & 0.000 \\
Relationship with Manager & 0.755 & 0.000 \\
\hline
\end{tabular}

\subsection{Reliability Analysis}

The reliability analysis is performed for each dependent and independent variables similar to the factor analysis. According to Sekaran (2003), the minimum acceptance criteria of reliability are the Cronbach's Alpha value should exceed 0.5 and high reliability is reflected from Cronbach's Alpha above 0.8. The findings of this study showed Cronbach's Alpha value for the three variables were above 0.5. The Transactional Leader, Transformational Leadership and Situational constituted $0.577,0.721$ and 0.890 respectively. The results are reflected in the Table 3 below.

Table 3 Summary of Cronbach's Alpha for independent variable (leadership styles) and dependent variable (employee adaptability)

\begin{tabular}{lc}
\hline Independent variables & Cronbach's Alpha \\
\hline Transactional Leadership & 0.577 \\
Transformational Leadership & 0.721 \\
Situational Leadership & 0.890 \\
\hline Dependent variables & Cronbach's Alpha \\
\hline Performance & 0.949 \\
Turnover & 0.551 \\
Participation & 0.906 \\
Relationship with Manager & 0.853 \\
\hline
\end{tabular}

\subsection{Correlation Analysis}

The correlation analysis is a statistical method used to observe all the existence of relationship between independent variables and dependent variables (Sekaran, 2006). The analysis is performed to see whether the two variables are perfectly relayed in a positive liner relationship, negative linear relationship or no linear relationship between them.

The study showed that the correlation between leadership styles and performance is significant for all the leadership styles. Transactional Leadership showed $p=0.009$, Transformational Leadership $p=0.018$ and Situational Leadership $\mathrm{p}=0.000$.

The correlation between leadership styles and turnover showed Transactional Leadership is significant with $\mathrm{p}=$ 0.000 , but Transformational and Situational Leadership are not significant, $\mathrm{p}=0.075$ and $\mathrm{p}=0.508$ respectively.

The correlation between leadership styles and participation indicated that the Transactional and Situational Leadership are significant with $\mathrm{p}=0.009$ and $\mathrm{p}=0.000$ respectively while Transformational Leadership constituted significance level $\mathrm{p}=0.182$.

Lastly, the correlation between leadership and relationship with managers indicated that only Situational Leadership is significant with $\mathrm{p}$ equal to 0.000 . Transactional and Transformational Leaderships proofed not 
significant to employees' relationship with manager with $p=0.187$ and $p=0.126$ respectively. The summary of the correlation is shown in the Table 4 below.

Table 4. Summary of regression statistic for dependent variable (performance, turnover, participation and relationship with manager)

\begin{tabular}{|c|c|c|c|c|c|c|}
\hline \multicolumn{7}{|c|}{ Dependent variable (Performance) } \\
\hline \multicolumn{7}{|c|}{ Unstandardized } \\
\hline \multicolumn{7}{|c|}{ Coefficients } \\
\hline Model & $\mathrm{B}$ & Std. Error & $\mathrm{T}$ & Sig. & R Square & Adjusted R Square \\
\hline Constant & 0.286 & 0.403 & 0.71 & 0.48 & 0.692 & 0.683 \\
\hline Transactional Leadership & -0.207 & 0.078 & -2.654 & 0.009 & & \\
\hline Transformational Leadership & 0.289 & 0.12 & 2.395 & 0.018 & & \\
\hline Situational Leadership & 0.819 & 0.103 & 7.919 & 0 & & \\
\hline \multicolumn{7}{|c|}{ Dependent variable (Turnover) } \\
\hline \multicolumn{7}{|c|}{ Unstandardized } \\
\hline \multicolumn{7}{|c|}{ Coefficients } \\
\hline Model & $\mathrm{B}$ & Std. Error & $\mathrm{T}$ & Sig. & R Square & Adjusted R Square \\
\hline Constant & 1.176 & 0.468 & 2.51 & 0.014 & 0.153 & 0.128 \\
\hline Transactional Leadership & 0.351 & 0.091 & 0.363 & 0 & & \\
\hline Transformational Leadership & 0.252 & 0.14 & 0.239 & 0.075 & & \\
\hline Situational Leadership & -0.08 & 0.12 & -0.089 & 0.508 & & \\
\hline \multicolumn{7}{|c|}{ Dependent variable (Participation) } \\
\hline \multicolumn{7}{|c|}{ Unstandardized } \\
\hline \multicolumn{7}{|c|}{ Coefficients } \\
\hline Model & B & Std. Error & $\mathrm{T}$ & Sig. & R Square & Adjusted R Square \\
\hline Constant & 1.685 & 0.511 & 3.295 & 0.001 & 0.401 & 0.383 \\
\hline Transactional Leadership & -0.263 & 0.099 & -2.659 & 0.009 & & \\
\hline Transformational Leadership & 0.205 & 0.153 & 1.343 & 0.182 & & \\
\hline Situational Leadership & 0.513 & 0.131 & 3.904 & 0 & & \\
\hline \multicolumn{7}{|c|}{ Dependent variable (Relationship with Manager) } \\
\hline \multicolumn{7}{|c|}{ Unstandardized } \\
\hline \multicolumn{7}{|c|}{ Coefficients } \\
\hline Model & $\mathrm{B}$ & Std. Error & $\mathrm{T}$ & Sig. & R Square & Adjusted R Square \\
\hline Constant & 1.138 & 0.384 & 2.962 & 0.004 & 0.516 & 0.502 \\
\hline Transactional Leadership & -0.099 & 0.074 & -1.328 & 0.187 & & \\
\hline Transformational Leadership & 0.177 & 0.115 & 1.543 & 0.126 & & \\
\hline Situational Leadership & 0.559 & 0.099 & 5.668 & 0 & & \\
\hline
\end{tabular}

\subsection{Interpretation of Analysis}

From the results obtained, we can conclude the following:

- The leadership style has an impact on employee adaptability.

- Transactional Leadership has an impact on employees' performance, turnover and participation only.

- Transformational Leadership has an impact on employees' performance only. 
- Situational Leadership has an impact on employees' performance, participation and relationship with manager.

\section{Conclusion}

\subsection{Findings}

This research is to study about the employees' adaptability towards different leadership stylespracticed in call centers in the telecommunication industry. The findings of the current study provided strong evidence that managers' leadership styles have an influence on the employees' performance, turnover, participation and relationship with them in the call center business unit.

The study revealed that the transactional leaders influence the employees' adaptability in the aspect of performance, turnover and participation, leaving less focus on the relationship with the manager. This could be reasoned by the fact that most employees are motivated by rewards. While, the Transformational Leadership is solely influenced the employee performance in the call center. This could be because the employees are managed by female managers. And finally, the findings showed that Situational Leadership has significant influence on the employees' performance, participation and relationship with manager. This can be due to managers equip themselves with this style of leadership and demonstrate in particular situations. The findings in this study did not deny the three types of leaderships are correlated to employees' performance, turnover, participation and relationship with manager. So, the eight hypotheses are verified in this study. The final framework of this research was established as per Figure 1 attached below.

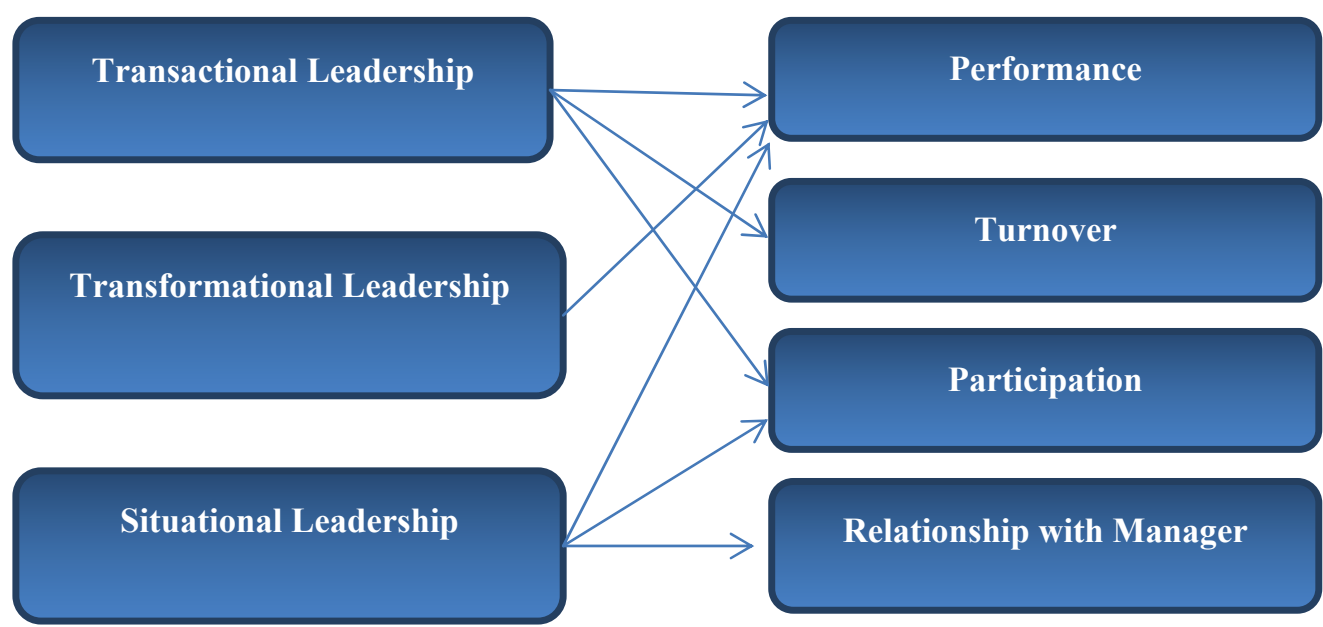

Figure 1. Final framework

\subsection{Future Research}

Since this research focused on the employee adaptability towards different leadership styles, it is possible to study hypothetical relationship between the extend of the emotions at the workplace against employees' adaptability. Future research also should be carried out on the individual leadership styles in the call centers of the telecommunication industry itself as it may provide an in depth knowledge on the most suitable leadership style. Also, future research can be conducted in other call centers in other industries such as banking, public sectors and airlines to understand better on the approaches portrayed and preferences in this sector. All the above topics will provide us a better knowledge on the leadership styles and their impact on the employees' adaptability.

\section{References}

Aragon-Correa, J. A., Garcia-Morales, V. J., \& Cordon-Pozo, E. (2007). Leadership and organizational learning's role on innovation and performance: Lessons from Spain. Industrial Marketing Management, 36(3), 349-359.

Avolio, B. J., Walumbwa, F. O., \& Weber, T. J. (2009). Leadership: Current theories, research, and future $\begin{array}{lllll}\text { directions. The Annual Review of Psychology, 60, 421-449. } & \text {. }\end{array}$ http://dx.doi.org/10.1146/annurev.psych.60.110707.163621 
Birasnav, M., Rangnekar, S., \& Dalpati, A. (2011). Transformational leadership and human capital benefits: The role of knowledge management. Leadership \& Organization Development Journal, 32(2), 106-126. http://dx.doi.org/10.1108/01437731111112962

Boehnke, K., Bontis, N., DiStefano, J. J., \& DiStefano, A. C. (2003). Transformational leadership: An examination of cross-national differences and similarities. Leadership \& Organization Development Journal, 24(1), 5-15. http://dx.doi.org/10.1108/01437730310457285

Boerner, S., Eisenbeiss, S. A., \& Griesser, D. (2007). Follower behavior and organizational performance: The impact of transformational leaders. Journal of Leadership and Organizational Studies, 13(3), 15-26. Retrieved October 7, 2011, from http://www.entrepreneur.com/tradejournals/article/159696522.html

Carruthers, M. (2010). Reduce employee turnover. Systemic Solutions. Retrieved September 23, 2011, from http://www.systemiccoaching.com/attrition.htm

Chen, J. C., \& Silverthorne, C. (2005). Leadership effectiveness, leadership style and employee readiness. Leadership \& Organization Development Journal, 26(4), 280-288. http://dx.doi.org/10.1108/01437730510600652

De Jong, J. P. J., \& Den Hartog, D. N. (2007). How leaders influence employees' innovative behavior. European Journal of Innovation Management, 10(1), 41-64. http://dx.doi.org/10.1108/14601060710720546

Employee. (2010, February). Stakeholder. Retrieved May 1, 2012, from http://www.stakeholdermagazine.com

Felfe, J., \& Schyns, B. (2006). Personality and the perception of transformational leadership: The impact of extraversion, neuroticism, personal need for structure and occupational self-efficacy. Journal of Applied Social Psychology, 36(3), 708-739. http://dx.doi.org/10.1111/j.0021-9029.2006.00026.x

Gill, A. S. (2007). The role of trust in employee-manager relationship. International Journal of Contemporary Hospitality Management, 20(1), 98-103. http://dx.doi.org/10.1108/09596110810848613

Heslin, P. A., Vandewalle, D., \& Latham, G. P. (2006). Managers' implicit person theories and their subsequent $\begin{array}{llll}\text { employee } & \text { coaching. } & \text { Personnel }\end{array}$ http://dx.doi.org/10.1111/j.1744-6570.2006.00057.x

Holt, D. T., Armenakis, A. A., Feild, H. S., \& Harris, S. G. (2007). Readiness for organizational change: The systematic development of a scale. The Journal of Applied Behavioural Science, 43(2), 232-255. http://dx.doi.org/10.1177/0021886306295295

Ivancevich, J. M., Konopaske, R., \& Matteson, M. T. (2008). Organizational behavior and management (8th ed.). New York: McGraw Hill.

Jansen, J. J. P., Vera, D., \& Crossan, M. (2009). Strategic leadership for exploration and exploitation: The moderating role of environmental dynamism. The Leadership Quarterly, 20(1), 5-18. http://dx.doi.org/10.1016/j.leaqua.2008.11.008

Karami, M. (2006). Factors influencing adoption of online ticketing. Master's thesis. Lulea University of Technology. Retrieved from http://epubl.ltu.se/1653-0187/2006/45/LTU-PB-EX-0645-SE.pdf

Lambert, E. G., Hogan, N. L., \& Barton, S. M. (2001). The impact of job satisfaction on turnover intent: A test of a structural measurement model using a national sample of workers. The Social Science Journal, 38(2), 233-250. http://dx.doi.org/10.1016/S0362-3319(01)00110-0

Liu, X., \& Batt, R. (2010). How supervisors influence performance: A multilevel study of coaching and group management in technology-mediated services. Personnel Psychology, 63(2), 265-298. http://dx.doi.org/10.1111/j.1744-6570.2010.01170.x

McCann, M. (2009). Leadership can solve employee turnover in the high-tech field. Retrieved August 22, 2011, from http://EzineArticles.com/?expert=Michael_McCann

Motley, A. (Ed.). (2007). Leadership for the long haul. Business Officer Magazine. Retrieved July 22, 2011, from http://www.nacubo.org/x9514.xml

Mujtaba, B. G. (2009). Situational leadership and diversity management coaching skills. Journal of Diversity Management, 4(1), 1-12.

Nahavandi, A. (2006). The art and science of leadership (4th ed.). Upper Saddle River, NJ: Prentice Hall.

Nemanich, L. A., \& Keller, R. T. (2007). Transformational leadership in an acquisition: A field study of employees. The Leadership Quarterly, 18(1), 49-68. http://dx.doi.org/10.1016/j.leaqua.2006.11.003 
PENN Behavioral Health. (2008). Adapting to change at work: Effectively navigating the turmoil of organizational changes through adaptation. Retrieved August 23, 2011 from http://www.pennbehavioralhealth.org/documents/adapting_to_change.pdf

Raja, S., \& Palanichamy, P. (2011). The relationship between leadership styles and employee performance. Asia Pacific Journal of Research in Business Management, 2(1), 147-150.

Roy, R. C. (2006). Leadership, corporate culture and financial performance. Unpublished doctoral dissertation. San Francisco, CA: University of San Francisco.

Sagie, A., \& Koslowsky, M. (1996). International replication note decision type, organisational control, and acceptance of change: An integrative approach to participative decision making. Applied Psychology, 45(1), 85-92. http://dx.doi.org/10.1111/j.1464-0597.1996.tb00850.x

Sekaran, U. (2003). Research methods for business (4th ed.). Hoboken, NJ: John Wiley \& Sons.

Sekaran, U. (2006). Research methods for business: A skill building approach. Singapore: John Wiley \& Sons, Inc.

Snell, A. J., \& Dickson, G. (2011). Optimizing health care employees' newly learned leadership behaviours. Leadership in Health Services, 24(3), 183-195. http://dx.doi.org/10.1108/17511871111151090

Truskie, S. (2008). Building an adaptive workforce. Adaptable Leadership, LLC - Building Leaders for Changing Times. Retrieved September 2, 2011, from http://www.adaptableleadership.com

Walsh, K., \& Taylor, M. S. (2007). Developing in-house careers and retaining management talent: What hospitality professionals want from their jobs? Cornell Hospitality Quarterly, 48(2), 163-182. http://dx.doi.org/10.1177/0010880407300521

Wilson, D. G. (2010). Building bridges for change: How leaders enable collective change in organizations. Development and Learning in Organizations, 24(1), 21-23. http://dx.doi.org/10.1108/14777281011010488

Wright, T. A., \& Bonett, D. G. (2007). Job satisfaction and psychological well being as non-additive predictors of workplace turnover. Journal of Management, 33(2), 141-160. http://dx.doi.org/10.1177/0149206306297582

Xenikou, A., \& Simosi, M. (2008). Organizational culture and transformational leadership as predictors of business unit performance. Journal of Managerial Psychology, 21(6), 566-579. http://dx.doi.org/10.1108/02683940610684409

\section{Copyrights}

Copyright for this article is retained by the author(s), with first publication rights granted to the journal.

This is an open-access article distributed under the terms and conditions of the Creative Commons Attribution license (http://creativecommons.org/licenses/by/3.0/). 